\title{
Spatial and temporal patterns of the emerging tick-borne pathogen Borrelia miyamotoi in blacklegged ticks (Ixodes scapularis) in New York
}

\author{
F. Keesing ${ }^{1 *}$, D. J. McHenry², M. H. Hersh ${ }^{3}$ and R. S. Ostfeld ${ }^{4}$
}

\begin{abstract}
Borrelia miyamotoi, a bacterium that causes relapsing fever, is found in ixodid ticks throughout the northern hemisphere. The first cases of human infection with B. miyamotoi were identified in 2011. In the eastern USA, blacklegged ticks (Ixodes scapularis) become infected by feeding on an infected vertebrate host, or through transovarial transmission. We surveyed B. miyamotoi prevalence in ticks within forested habitats in Dutchess County, New York, and identified possible reservoir hosts. To assess spatial variation in infection, we collected questing nymphal ticks at $>150$ sites. To assess temporal variation in infection, we collected questing nymphs for 8 years at a single study site. We collected questing larval ticks from nine plots to estimate the amount of transovarial transmission. To evaluate potential reservoir hosts, we captured 14 species of mammal and bird hosts naturally infested with larval blacklegged ticks and held these hosts in the laboratory until ticks fed to repletion and molted to nymphs. We determined infection for all ticks using quantitative polymerase chain reaction. The overall infection prevalence of questing nymphal ticks across all sites was $\sim 1 \%$, but prevalence at individual sites was as high as $9.1 \%$. We detected no significant increase in infection through time. Only $0.4 \%$ of questing larval ticks were infected. Ticks having fed as larvae from short-tailed shrews, red squirrels, and opossums tended to have higher infection prevalence than did ticks having fed on other hosts. Further studies of the role of hosts in transmission are warranted. The locally high prevalence of B. miyamotoi in the New York/ New England landscape suggests the importance of vigilance by health practitioners and the public.
\end{abstract}

Keywords: Borrelia miyamotoi, Blacklegged tick, Emerging infectious disease, Ixodes scapularis, Reservoir host, Disease ecology

\section{Introduction}

First described from ticks in Japan [9], Borrelia miyamoto $i$ is a member of a group of bacteria that cause relapsing fever. Since its discovery in Asia, B. miyamotoi has been found in North America [21, 26] and Europe [8]. A congener of Borrelia burgdorferi, the pathogen that causes Lyme disease, Borrelia miyamotoi has been identified in

*Correspondence: keesing@bard.edu

1 Program in Biology, Bard College, Annandale-on-Hudson, NY 12504, USA

Full list of author information is available at the end of the article all of the major tick vectors that transmit the Lyme bacterium among hosts, including Ixodes scapularis in the eastern USA [26], Ixodes pacificus in the western USA [20], and Ixodes persulcatus and Ixodes ricinus in Eurasia $[8,9]$. It has also been found in vectors that specialize on non-human hosts, including Ixodes dentatus, which feeds primarily on birds and rabbits [11].

Although B. miyamotoi had been found in ticks from across the northern hemisphere, its role as a human pathogen was recognized only in 2011, when 46 patients in Russia tested positive for B. miyamotoi infection [24]. Infected patients suffered high fevers and other 
influenza-like symptoms [24]. Relapsing fever occurred in $11 \%$ of these patients and $5 \%$ developed a bulls-eye rash (erythema migrans) [24]. In 2013, the first patients in the USA were identified, with cases in New Jersey and Massachusetts [10, 17]. The role of B. miyamotoi in human cases of tick-borne illness is now being more broadly investigated (e.g. 7, 32).

In North America, B. miyamotoi occurs at low $(<5 \%)$ prevalence in ticks at the sites where it has been identified $[1,6,16,19-21,26,29,30,34]$. Ticks can acquire $B$. miyamotoi infection in three ways. First, based on laboratory studies, B. miyamotoi can be transmitted transovarially from infected female ticks to their larval offspring [3, $12,25,26]$. Second, ticks can acquire infection through co-feeding, in which infected ticks transmit infection directly to uninfected ticks feeding on the same host at the same time [26]. Finally, ticks can acquire infection by feeding on hosts infected with $B$. miyamotoi, though the efficiency of transmission appears to be lower for $B$. miyamotoi than it is for B. burgdorferi [26]. Once ticks acquire infection, they appear to maintain infection through adulthood [26].

Limited data are available on which host species infect feeding ticks. In Connecticut, nymphal ticks infected with B. miyamotoi were collected from an eastern chipmunk (Tamias striatus), three raccoons (Procyon lotor), an eastern gray squirrel (Sciurus carolinensis), and three pine voles (Microtus pinetorum) [1, 13]. In Michigan, northern cardinals (Cardinalis cardinalis) were responsible for feeding over $70 \%$ of the I. dentatus ticks that were removed from birds and later found to be infected with $B$. miyamotoi [11], suggesting that cardinals were more likely to infect ticks than other bird species in the study. However, ticks in the study were removed before feeding to repletion, which might have affected patterns of transmission. No ticks collected from eastern cottontails (Sylvilagus floridanus) were infected with B. miyamotoi [11]. In Tennessee, wild turkeys (Meleagris gallopavo) had high seroprevalence of antibodies against B. miyamotoi [27]. Studies on other common wildlife species in endemic areas are lacking.

In the northeastern USA, Borrelia miyamotoi circulates in the blacklegged tick (I. scapularis), the same tick vector that harbors a suite of other pathogens of humans, including Borrelia burgdorferi, as well as Anaplasma phagocytophilum and Babesia microti, which cause anaplasmosis and babesiosis, respectively. In previous studies, co-infections of ticks with B. miyamoto $i$ and $B$. burgdorferi have been found to be neither more nor less frequent than expected by chance [1], but see Tokarz et al. [29].

Recent research in parts of Europe and the USA has shown that tick infection prevalence is highly variable at a large geographic scale [5]. For example, infection prevalence at individual sites in 13 counties in California varied from a high of $15.4 \%$ of ticks infected to a low of $1.2 \%$, with more than half of sites having no infected ticks.

To address the potentially emerging public health challenge posed by $B$. miyamotoi transmission and consequent disease, we analyzed patterns of infection in ticks in Dutchess County, New York, an area of high incidence of several tick-borne diseases [29]. In a recent survey, infection prevalence for B. miyamotoi in Dutchess County was reported as quite low, with $0.5 \%$ of ticks infected at the one site sampled [5]. To determine spatial variation in tick infection with $B$. miyamoto $i$ at a regional scale, we collected questing nymphal ticks from $>150$ sites in Dutchess County over 2 years. We also collected questing larval ticks to determine the frequency of infection resulting from transovarial transmission. Using ticks previously collected for studies of other pathogens, we conducted a preliminary investigation on a suite of vertebrate hosts to determine which species might infect blacklegged ticks with B. miyamotoi.

\section{Methods \\ Collecting ticks from forests}

We sampled questing nymphal ticks (I. scapularis) in June 2011 (107 sites) and June 2012 (53 sites) in forested locations throughout Dutchess County, New York. We selected sites using a geographic information systems map of forested and non-forested land cover digitized from aerial orthophotos generated in 2009. We generated an initial candidate list of 2500 random points using a random point overlay. These points were then stratified by the percentage of forest cover in the surrounding landscape, to provide equal representation along a gradient of forest cover, from extensively forested to highly fragmented. We eliminated sites when access was poor or property owners could not be located or recruited. Details on site selection and sampling locations are provided in Hersh et al. [15].

Between 2006 and 2013, we also collected questing nymphal ticks from six 2.25-ha plots at a single study site at the Cary Institute of Ecosystem Studies in Millbrook, New York. Forests at the Cary Institute are typical of the eastern deciduous forests of New York and New England. The site is dominated by oaks (Quercus rubra and Quercus prinus) in the overstory, with primarily oak and sugar maple (Acer saccharum) seedlings, maple-leaved viburnum (Viburnum acerifolium), witch hazel (Hamamelis virginiana), and ironwood (Ostrya virginiana) in the understory. More information about the Cary Institute study sites and tick sampling protocols are provided in Ostfeld et al. [23]. 
At all sites at which we collected questing nymphal ticks, we did so by dragging corduroy cloths $\left(1 \mathrm{~m}^{2}\right)$ along 400-m transects in each site once or twice in a given year during the annual peak in nymphal questing activity [22]. We collected ticks from the cloths every $15-30 \mathrm{~m}$ and froze questing nymphs in liquid nitrogen upon collection. Larvae were flash-frozen in liquid nitrogen in pools of ten. To estimate prevalence at each site, we tested 20-30 nymphs individually (i.e. not in pools).

To test for transovarial transmission, we collected questing larval ticks in August 2013 from nine plots distributed throughout the 1000-ha grounds of the Cary Institute using the same techniques described above. We tested pools of ten larvae. Larvae for these pools were randomly selected from multiple drag samples within each plot to avoid dominance by specific areas within plots.

\section{Collecting ticks from hosts}

To determine which species play a role in infecting larval ticks with $B$. miyamotoi, we determined whether ticks were infected following larval meals on seven mammal and two bird species. For detailed methods, see Hersh et al. [14]. Briefly, we captured host individuals in central Dutchess County, New York, during the peak abundance of larval blacklegged ticks (I. scapularis), from July to September in 2008, 2009, and 2010. We held captured individuals for 3 days in cages with wire mesh floors. Cages were suspended over pans lined with wet paper towels so that ticks could be collected after feeding to repletion and dropping from hosts. We maintained engorged larvae in moistened glass vials until they molted into the nymphal stage and then froze them in liquid nitrogen and stored them at $-80{ }^{\circ} \mathrm{C}$. We conducted all animal care and husbandry with approval from the Institutional Animal Care and Use Committee of the Cary Institute of Ecosystem Studies. We analyzed tick infection for individual hosts that produced at least 15 larvae that molted into nymphs. Host species for which we had adequate samples of ticks included short-tailed shrews (Blarina brevicauda), veeries (Catharus fuscescens), Virginia opossums (Didelphis virginiana), gray catbirds (Dumetella carolinensis), southern flying squirrels (Glaucomys volans), wood thrushes (Hylocichla mustelina), striped skunks (Mephitis mephitis), white-footed mice (Peromyscus leucopus), raccoons (Procyon lotor), gray squirrels (Sciurus carolinensis), masked shrews (Sorex cinereus), eastern chipmunks (Tamias striatus), American red squirrels (Tamiasciurus hudsonicus), and American robins (Turdus migratorius).

\section{Extracting and amplifying DNA}

We extracted total genomic DNA from ticks using either the DNeasy or DNeasy 96 Blood and Tissue kit (Qiagen, Hilden, Germany) or the Gentra PureGene Tissue Kit (Qiagen). B. miyamotoi was detected using quantitative polymerase chain reaction (qPCR) as described by Platonov et al. [24]. Briefly, we used a TaqMan Probe with 5'-6FAM and 3'-TAMRA (Life Technologies, Grand Island, NY) and iQ Supermix (Bio-Rad, Hercules, CA). Thermal cycling was conducted in a C1000 Thermal Cycler with the CFX96 Real-Time System (Bio-Rad). Ultrapure water served as negative controls. The qPCR target sequence was amplified from SCID + B. miyamotoi-positive mouse blood, provided by Sam Telford III (Tufts University, North Grafton, MA) and cloned into the pCR2.1-TOPO plasmid (Life Technologies). Plasmid extracted from confirmed clones was used as our positive control. Three replicates per tick were amplified. A DNA was considered positive for $B$. miyamoto $i$ if at least one replicate was called positive as determined by the default settings for the qPCR machine software (CFX Manager Software 3.0; Bio-Rad).

\section{Analysis}

Larval infection from pooled samples was calculated with the Pooled Prevalence Calculator ([28], http://epitools. ausvet.com.au) using maximum likelihood estimation. To determine an overall estimate of prevalence, we calculated prevalence independently for each of the nine plots from which we collected larvae, and then took the mean of those values.

\section{Results}

Spatial variation

For our regional sampling, we collected a total of 3647 nymphal ticks at 107 sites in 2011 and 53 sites in 2012. Fifty-one of these sites were sampled in both years, while 58 sites were sampled in only 1 year. The mean infection prevalence of ticks summed over both years was $1.16 \%$ $(2.09 \% \mathrm{SD})$. Across both years, the maximum prevalence we detected at an individual site was 9.1\% (Fig. 1; Additional file 1: Table S1). At $70.6 \%$ of sites (77 out of 109 total), we detected no B. miyamotoi (Fig. 1; Additional file 1: Table S1). For the 51 sites we sampled in both years, there was no strong correlation in infection prevalence across years (Kendall's $\tau=0.154$ ).

\section{Temporal variation}

At the single site we sampled over 8 years, there was no significant temporal trend (Fig. 2). Although we collected no ticks infected with B. miyamotoi in 2006 and 2007, the $95 \%$ confidence intervals for these years overlap with 


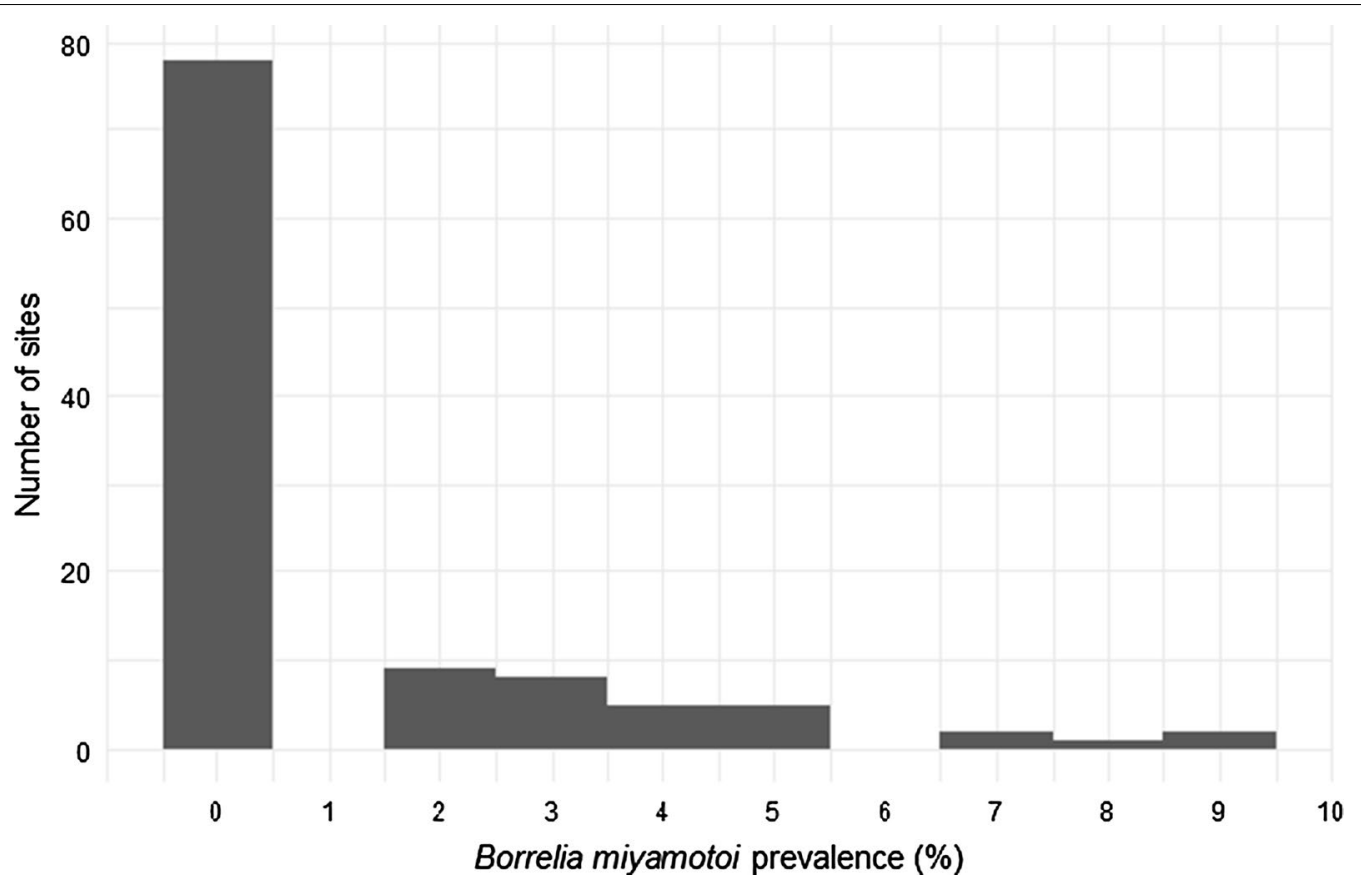

Fig. 1 Prevalence of infection with Borrelia miyamotoi in nymphal ticks from Dutchess County, New York, collected at 107 sites in 2011 and 53 sites in 2012. Data from the 51 sites sampled in both years are pooled. At each site, prevalence was estimated from a sample of 20-30 ticks

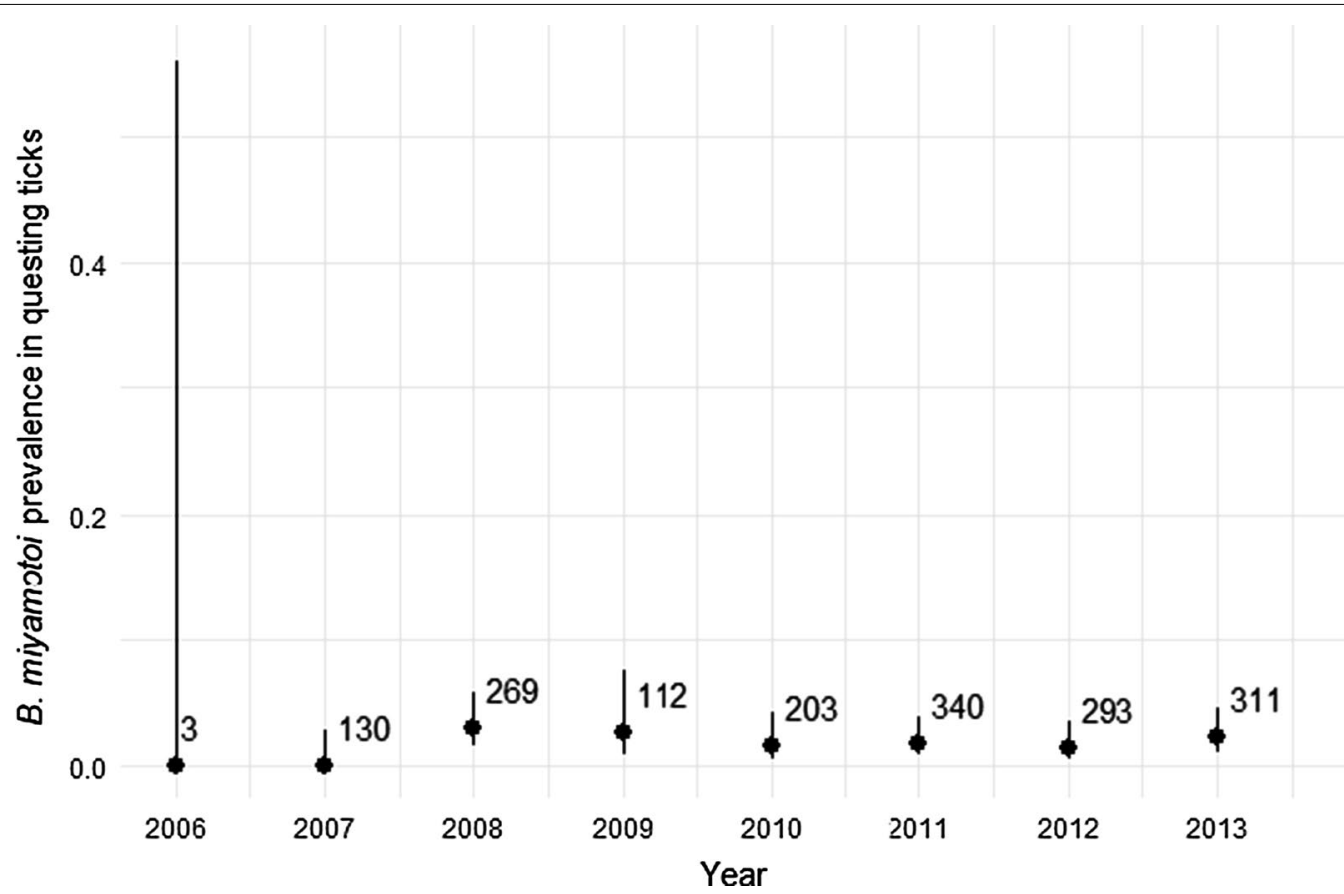

Fig. 2 Proportion of ticks infected with B. miyamotoi at a single site from 2006 to 2013 . Bars represent $95 \%$ confidence intervals; numbers on figure indicate sample sizes 
those for subsequent years. After detection of the first infected nymphs in 2008 , we found that $1-3 \%$ of questing nymphal ticks were infected at this site each year with no apparent increase or decrease through time.

\section{Larval infection}

To determine levels of transovarial transmission in the field, we tested 216 pools of ten larvae from nine plots, with 23-26 pools from each plot. Eight of the 216 pools tested positive for B. miyamotoi $(0.4 \% \pm 0.2 \% \mathrm{SE})$. The mean infection prevalence of larvae, calculated from the pooled data for each of the nine plots, was $0.4 \%$, or four infected larvae per 1000 larvae. Four of the nine plots had infected larvae, and infection prevalences at these plots varied from a low of $0.4 \%$ to a high of $1.8 \%$. The remaining five plots had no infected larval pools.

\section{Reservoir assays}

We determined infection with B. miyamotoi for 3280 ticks that had fed on 181 individual hosts of 14 common species of vertebrate hosts. We tested a mean of 17.3 ( \pm 0.5 , SE of the mean) ticks per individual host. Of the ticks we tested, 38 (1.2\%) were infected with $B$. miyamotoi. Hosts from which at least one infected tick was obtained were assumed to be infected, allowing us to estimate infection prevalence at the level of host species. Short-tailed shrews (B. brevicauda), gray squirrels (S. carolinensis), American red squirrels (Tamiasciurus hudsonicus), American robins (Turdus migratorius), and Virginia opossums (Didelphis virginiana) all had prevalence values of $20 \%$ or higher, while some hosts, including gray catbirds (Dumetella carolinensis) and veeries (C. fuscescens), had zero prevalence (Table 1; Additional file 1: Table S1).

\section{Discussion}

At sites in Dutchess County, New York, the overall infection prevalence of questing nymphal ticks with $B$. miyamotoi was just over 1\%, though prevalence at individual sites was as high as $9.1 \%$. Larval infection prevalence, and therefore the risk of transmission from bites of larval ticks, was lower, with only $0.4 \%$ of questing larvae infected. Short-tailed shrews, red squirrels, and opossums appear to be potential reservoirs for the pathogen, as ticks that had fed on these hosts were highly likely to have acquired infection from these hosts during their larval meal. Our data provide one of the few field estimates of transovarial transmission to larval Ixodes ticks [3, 31], and identify a suite of potential new reservoirs for the pathogen.

We did not detect $B$. miyamotoi in nymphal ticks at $70.6 \%$ of sites. Our failure to detect B. miyamoto $i$ at any given site could have been due to sampling error, which is particularly likely with a rare pathogen. If we assume that $1 \%$ of ticks are infected with B. miyamotoi, there is an $80 \%$ chance that we would fail to detect an infection

Table 1 Host species from which replete larval blacklegged ticks were collected, allowed to molt into nymphs, and then tested using quantitative polymerase chain reaction for the presence of Borrelia miyamotoi

\begin{tabular}{|c|c|c|c|c|}
\hline Species & $n$ & Number of hosts infected & Prevalence (\%) & $\begin{array}{l}\text { Mean ticks } \\
\text { tested/host }\end{array}$ \\
\hline American robin (Turdus migratorius) & 20 & 4 & 20 & 17.3 \\
\hline Short-tailed shrew (Blarina brevicauda) & 29 & 10 & 34 & 18.8 \\
\hline Virginia opossum (Didelphis virginiana) & 27 & 6 & 22 & 19.7 \\
\hline Southern flying squirrel (Glaucomys volans) ${ }^{\mathrm{a}}$ & 7 & 0 & 0 & 12.4 \\
\hline Gray catbird (Dumetella carolinensis) & 18 & 0 & 0 & 16.6 \\
\hline Striped skunk (Mephitis mephitis) ${ }^{a}$ & 2 & 0 & & 15.5 \\
\hline White-footed mouse (Peromyscus leucopus) & 38 & 2 & 5 & 19.7 \\
\hline Raccoon (Procyon lotor) & 26 & 2 & 8 & 19.3 \\
\hline Gray squirrel (Sciurus carolinensis) & 20 & 1 & 5 & 17.9 \\
\hline Masked shrew (Sorex cinereus) ${ }^{\mathrm{a}}$ & 6 & 0 & 0 & 6.8 \\
\hline American Red squirrel (Tamiasciurus hudsonicus) & 15 & 4 & 2 & 19.8 \\
\hline Eastern chipmunk (Tamias striatus) & 23 & 3 & 13 & 16.0 \\
\hline Veery (Catharus fuscescens) & 22 & 0 & 0 & 20.2 \\
\hline Wood thrush (Hylocichla mustelina) & 28 & 1 & 4 & 17.7 \\
\hline
\end{tabular}

Because some of the larval ticks might have been infected prior to host feeding (via transovarial transmission), actual transmission from host to tick cannot be specified.

$n$ Number of individuals of each host species from which ticks were obtained and tested for infection, Prevalence percentage of each host species producing at least one infected tick

a Species for which $n<15$, rendering estimates of prevalence unreliable 
when sampling 20 ticks from a site. Thus, our estimate of the percentage of sites with $B$. miyamoto $i$ is conservative and provides a lower bound of risk of human exposure.

At the $29.4 \%$ of sites at which we did detect infection, prevalence was as high as $9.1 \%$, suggesting high spatial variation in risk. Infection prevalence of nymphal $I$. scapularis with $B$. burgdorferi at similar levels has been associated with substantial burdens of Lyme disease in local human populations [18]. Consequently, it is possible that human infections are much more common than has been reported; alternatively, tick-to-human transmission of $B$. miyamotoi might be considerably less likely than tick-tohuman transmission of B. burgdorferi. The lack of a correlation in prevalence levels between years suggests that local risk may vary substantially from year to year, but only long-term monitoring can establish this definitively. Although our statistical analysis does not support a conclusion of changing prevalence through time, we failed to detect the pathogen during the first 2 years of sampling, which is consistent with its arrival in 2008.

By collecting replete larval blacklegged ticks having fed from known hosts, we provide preliminary information on possible natural reservoirs for B. miyamotoi transmission. We found that several species of mammalian and avian hosts, especially American robins, short-tailed shrews, Virginia opossums, and American red squirrels, showed high prevalence of infection, ranging from 20 to $34 \%$. Because some of the host-fed ticks in which we detected $B$. miyamotoi infection might have acquired infection transovarially, and thus were infected prior to feeding on these hosts, we cannot estimate reservoir competence of the vertebrate hosts. Nevertheless, with infection prevalence for questing larval ticks with $B$. miyamotoi at roughly $1 \%$, we suspect that hostto-tick transmission was responsible for the majority of the positive nymphs. Further studies of reservoir status will be required before host species can be compared quantitatively.

Borrelia miyamotoi coexists in the northeastern USA with a suite of other tick-borne pathogens including Borrelia burgdorferi; Anaplasma phagocytophilum, which causes granulocytic anaplasmosis; Babesia microti, which causes human babesiosis; and Powassan virus, which causes Powassan viral encephalitis. All of these pathogens initially cause generalized flulike symptoms in afflicted humans, making differential diagnosis challenging $[2,4]$. Blacklegged ticks can be co-infected with $>1$ of these pathogens (e.g. [15]), although patterns of co-infection with $B$. miyamotoi have not been thoroughly examined. It is not yet clear whether standard diagnostic tests for Lyme disease and anaplasmosis can differentiate these illnesses from infection with $B$. miyamotoi $[2,24,33]$. Fortunately, evidence to date suggests that $B$. miyamotoi responds to treatment with antibiotics that are commonly used to treat Lyme disease and anaplasmosis $[4,33]$.

The presence of B. miyamotoi in the New York/New England landscape suggests the importance of vigilance by public health practitioners. In principle, the greatest risk for human exposure to B. miyamotoi is during May and June in the northeastern USA, coincident with the peak of questing behavior by nymphal ticks. However, in practice, August and September might also prove to be times of risk. Questing larval ticks, which are active during these months, can be infected with $B$. miyamotoi, but health professionals and the public are less familiar with the risk of tick-borne illnesses during late summer.

\section{Supplementary Information}

The online version contains supplementary material available at https://doi. org/10.1186/s13071-020-04569-2.

Additional file 1: Table S1.

\section{Acknowledgments}

We thank Mike Tibbetts and Mitch LeSage for laboratory assistance, Jesse Brunner for help with data, and Shannon Duerr, Kelly Oggenfuss, and numerous project assistants for help collecting and caring for ticks and hosts in the field and lab. Sam Telford III graciously provided mouse blood to serve as a positive control.

\section{Authors' contributions}

FK and RSO designed the study and oversaw the collection of field data. FK and RSO wrote the initial draft, and all the other authors reviewed and edited the manuscript. DJM and MH collected the data on infection. MH and FK conducted the statistical analyses. All the authors read and approved the final manuscript.

\section{Funding}

This work was supported by grant numbers DEB 0444585, DEB 0949702 , and DEB 1456527 from the Long-Term Research in Environmental Biology program of the United States National Science Foundation (NSF), as well as DEB 0813041 from the Ecology and Evolution of Infectious Diseases program of NSF, and EPA STAR grant 83489701

Availability of data and materials

Data are available in Additional file 1: Table S1.

\section{Ethics approval and consent to participate}

Research on vertebrate animals was conducted under Cary Institute Institutional Animal Care and Use Committee protocol 09-01.

\section{Consent for publication}

All the authors consent to publication.

\section{Competing interests}

The authors declare no competing financial interests.

\section{Author details}

${ }^{1}$ Program in Biology, Bard College, Annandale-on-Hudson, NY 12504, USA. ${ }^{2}$ Alson H. Smith Jr. Agricultural Research and Extension Center, Virginia Tech, Winchester, VA 22602, USA. ${ }^{3}$ Department of Biology, Sarah Lawrence College, Bronxville, NY 10708, USA. ${ }^{4}$ Cary Institute of Ecosystem Studies, PO Box AB, Millbrook, NY 12545, USA. 
Received: 5 November 2020 Accepted: 28 December 2020

Published online: 14 January 2021

\section{References}

1. Barbour AG, Bunikis J, Travinsky B, Hoen AG, Diuk-Wasser MA, Fish D, Tsao $J$ L. Niche partitioning of Borrelia burgdorferi and Borrelia miyamotoi in the same tick vector and mammalian reservoir species. Am J Trop Med Hyg. 2009;81:1120-31.

2. Branda JA, Rosenberg ES. Borrelia miyamotoi: a lesson in disease discovery. Ann Int Med. 2013;159:61-2.

3. Breuner NE, Hojgaard A, Replogle AJ, Boegler KA, Eisen L. Transmission of the relapsing fever spirochete, Borrelia miyamotoi, by single transovariallyinfected larval Ixodes scapularis ticks. Ticks Tick Borne Dis. 2018;9:1464-7.

4. Chowdri HR, Gugliotta JL, Berardi VP, Goethert HK, Molloy PJ, Sterling SL, Telford SR. Borrelia miyamotoi infection presenting as human granulocytic anaplasmosis: a case report. Ann Int Med. 2013;159:21-7.

5. Crowder CD, Carolan HE, Rounds MA, Honig V, Mothes B, Haag H, Nolte $\mathrm{O}$, et al. Prevalence of Borrelia miyamotoi in Ixodes ticks in Europe and the United States. Emerg Infect Dis. 2014;20:1678-82.

6. Dibernardo A, Cote T, Ogden NH, Lindsay LR. The prevalence of Borrelia miyamotoi infection, and co-infections with other Borrelia spp. in Ixodes scapularis ticks collected in Canada. Parasites Vectors. 2014:7:1-8.

7. Fonville M, Friesema IHM, Hengeveld PD, Docters van Leeuwen A, Jahfari S, Harms MG, et al. Human exposure to tickborne relapsing fever spirochete Borrelia miyamotoi, the Netherlands [letter]. Emerg Infect Dis. 2014;20:1244-5.

8. Fraenkel CJ, Garpmo U, Berglund J. Determination of novel Borrelia genospecies in Swedish Ixodes ricinus ticks. J Clin Microbiol. 2002;40:3308-12.

9. Fukunaga M, Takahashi Y, Tsuruta Y, Matsushita O, Ralph D, McClelland M, Nakao M. Genetic and phenotypic analysis of Borrelia miyamotoi sp. nov., isolated from the ixodid tick Ixodes persulcatus, the vector for Lyme disease in Japan. Int J Syst Bact. 1995;45:804-10.

10. Gugliotta JL, Goethert HK, Berardi VP, Telford SR. Meningoencephalitis from Borrelia miyamotoi in an immunocompromised patient. N Engl J Med. 2013;368:240-5.

11. Hamer SA, Hickling GJ, Keith R, Sidge JL, Walker ED, Tsao Jl. Associations of passerine birds, rabbits, and ticks with Borrelia miyamotoi and Borrelia andersonii in Michigan, USA. Parasites Vectors. 2012:5:231.

12. Han S, Lubleczyk C, Hickling GJ, Belperron AA, Bockenstedt LK, Tsao Jl. Vertical transmission rates of Borrelia miyamotoi in Ixodes scapularis collected from white-tailed deer. Ticks Tick Borne Dis. 2019;10:682-9.

13. Hanincova K, Kurtenbach K, Diuk-Wasser M, Brei B, Fish D. Epidemic spread of Lyme borreliosis, northeastern United States. Emerg Infect Dis. 2006:12:604-11.

14. Hersh MH, Tibbetts M, Strauss M, Ostfeld RS, Keesing F. Reservoir competence of wildlife host species for Babesia microti. Emerg Infect Dis. 2012;18:1951-7.

15. Hersh MH, Ostfeld RS, McHenry DJ, Tibbetts M, Brunner JL, Killilea ME, LoGiudice K, Schmidt KA, Keesing F. Co-infection of blacklegged ticks with Babesia microti and Borrelia burgdorferi is higher than expected and acquired from small mammals. PLoS ONE. 2014;9(6):e99348. https://doi. org/10.1371/journal.pone.0099348.

16. Johnson TL, Graham CB, Maes SE, Hojgaard A, Fleshman A, Boegler KA, Delory MJ, Slater KS, Karpathy SE, Bjork JK, Neitzel DF, Schiffman EK, Eisen RJ. Prevalence and distribution of seven human pathogens in host-seeking Ixodes scapularis (Acari: Ixodidae) nymphs in Minnesota, USA. Ticks Tick Borne Dis. 2018;9:1499-507.

17. Krause PJ, Narasimhan S, Wormser GP, Rollend L, Fikrig E, Lepore T, Barbour A, Fish D. Human Borrelia miyamotoi infection in the United States. N Engl J Med. 2013;368:291-3.
18. Lane RS, Piesman J, Burgdorfer W. Lyme borreliosis: relation of its causative agent to its vectors and hosts in North America and Europe. Ann Rev Entomol. 1991;36:587-609.

19. Marcos LA, Smith K, Reardon K, Weinbaum F, Spitzer ED. Presence of Borrelia miyamotoi infection in a highly endemic area of Lyme disease. Ann Clin Microbiol Antimicrob. 2020;19:22-5.

20. Mun J, Eisen RJ, Eisen L, Lane RS. Detection of a Borrelia miyamotoi sensu lato relapsing-fever group spirochete from Ixodes pacificus in California. J Med Entomol. 2006:43:120-3.

21. Ogden NH, Margos G, Aanensen DM, Drebot MA, Feil EJ, Hanincová K, et al. Investigation of genotypes of Borrelia burgdorferi in Ixodes scapularis ticks collected during surveillance in Canada. Appl Environ Microbiol. 2011;77:3244-54

22. Ostfeld RS, Canham CD, Oggenfuss K, Winchcombe RJ, Keesing F. Climate, deer, rodents, and acorns as determinants of variation in Lyme-disease risk. PLoS Biol. 2006;4:e145.

23. Ostfeld RS, Levi T, Keesing F, Oggenfuss K, Canham CD. Tick-borne disease risk in a forest food web. Ecology. 2018;99:1562-73.

24. Platonov AE, Karan LS, Kolyasnikova NM, Makhneva NA, Toporkova MG, Maleev W, Fish D, Krause PJ. Humans infected with relapsing fever spirochete Borrelia miyamotoi, Russia. Emerg Infect Dis. 2011;17:1816-23.

25. Rollend L, Bent SJ, Krause PJ, Usmani-Brown S, Steeves TK, States SL, Lepore T, et al. Quantitative PCR for detection of Babesia microti in Ixodes scapularis ticks and in human blood. Vector Borne Zoonotic Dis. 2013:13:784-90.

26. Scoles GA, Papero M, Beati L, Fish D. A relapsing fever group spirochete transmitted by Ixodes scapularis ticks. Vector Borne Zoonotic Dis. 2001;1:21-34.

27. Scott MC, Rosen ME, Hamer SA, Baker E, Edwards H, Crowder C, Tsao JI, Hickling GJ. High-prevalence Borrelia miyamotoi infection among wild turkeys (Meleagris gallopavo) in Tennessee. J Med Entomol. 2010;47:1238-42

28. Sergeant ESG. Epitools epidemiological calculators. AusVet Animal Health Services and Australian Biosecurity Cooperative Research Centre for Emerging Infectious Disease. 2014. http://epitools.ausvet.com.au.

29. Tokarz R, Jain K, Bennett A, Briese T, Lipkin WI. Assessment of polymicrobial infections in ticks in New York State. Vector Borne Zoonotic Dis. 2010;10:217-21.

30. Ullmann AJ, Gabitzsch ES, Schulze TL, Zeidner NS, Piesman J. Three multiplex assays for detection of Borrelia burgdorferi sensu lato and Borrelia miyamotoi sensu lato in field-collected Ixodes nymphs in North America. J Med Entomol. 2005:42:1057-62.

31. Van Duijvendijk G, Coipan C, Wagemakers A, Fonville M, Ersoz J, Oei A, Foldvari G, Hovius J, Takken W, Sprong H. Larvae of Ixodes ricinus transmit Borrelia afzelii and B. miyamotoi to vertebrate hosts. Parasites Vectors. 2016:9:97.

32. Wagemakers A, Staarink PJ, Sprong H, Hovius JWR. Borrelia miyamotoi: a widespread tick-borne relapsing fever spirochete. Trends Parasitol. 2015:31:260-9.

33. Wormser GP, Shapiro ED, Fish D. Borrelia miyamotoi: an emerging tickborne pathogen. Am J Med. 2018;132:136-7.

34. Wroblewski D, Gebhardt L, Prusinski MA, Meehan LJ, Halse TA, Musser KA. Detection of Borrelia miyamotoi and other tick-borne pathogens in human clinical specimens and Ixodes scapularis ticks in New York State, 2012-2015. Ticks Tick Borne Dis. 2017:8:407-11.

\section{Publisher's Note}

Springer Nature remains neutral with regard to jurisdictional claims in published maps and institutional affiliations. 